\title{
UM ESTUDO SOBRE DIZERES DE LICENCIANDOS COTISTAS NO PIBID: TRESS LANCHES, PROFESSORA?
}

\author{
A study on PIBID quota students' sayings: three snacks, teacher? \\ Carla Lynn REICHMANN \\ Universidade Federal da Paraíba, João Pessoa, Brasil/CNPq \\ Daniel Sousa MORAIS \\ Universidade Federal da Paraíba, João Pessoa, Brasil
}

\begin{abstract}
RESUMO: Situado na Linguística Aplicada, na perspectiva das vozes do sul (MOITA LOPES, 2006; KLEIMAN, 2013), este trabalho busca compreender como os dizeres de licenciandos desvelam voz de autor. Ancorada no Interacionismo Sociodiscursivo (BRONCKART, 1999, 2008; MACHADO, 2004) e na Clínica da Atividade (CLOT, [1999], 2007), analisou-se o trabalho docente de dois estudantes cotistas inseridos no PIBID Letras-Inglês na UFPB (MORAIS, 2017). De natureza qualitativa, e seguindo a proposta da autoconfrontação simples, conforme a referida Clínica, a discussão focaliza duas entrevistas propulsionadas pela filmagem de aulas dos colaboradores, que posteriormente, ao se verem, geraram as entrevistas, corpus da pesquisa. Foi verificada a saliência do tema 'conflitos' $e$, neste recorte sobre seis fragmentos, observa-se a emergência da voz de autor empírico, inscrevendo questões socioprofissionais como escrita e oralidade, preconceito e fome. Em suma, emergem novas vozes docentes, sugerindo o entrelaçamento de histórias de vida dos licenciandos cotistas e seus alunos.
\end{abstract}

PALAVRAS-CHAVE: Formação inicial; PIBID; Cotas; Interacionismo sociodiscursivo; Ciências do trabalho.

ABSTRACT: Situated in the field of Applied Linguistics, and in line with the perspective of southern voices (MOITA LOPES, 2006; KLEIMAN, 2013), this study aims at comprehending how the sayings of student-teachers unveil author's voice. Grounded in Sociodiscursive Interactionism (BRONCKART, 1999,2008; MACHADO 2004), and Clinic of Activity (CLOT, [1999], 2007), this qualitative study focuses on two undergraduate quota students involved with PIBID - English Letters, at UFPB (MORAIS, 2017; adopting the simple self-confrontation concept as per the above-mentioned Clinic, our discussion focuses on two interviews triggered by footage of the participants' classes. Therefore, on seeing themselves, participants'comments were also filmed, generating the corpus. The theme 'conflicts' is salient, and in this cross-section focusing on six emblematic fragments, the emergence of author's voice can be perceived, inscribing socioprofessional issues such as writing and speaking, prejudice and hunger. In sum, new teacher voices emerge, addressing inclusive education, and highlighting interwoven life stories.

KEY WORDS: Initial teacher education; PIBID; Quotas; Sociodiscursive interactionism; Labor Sciences. 


\begin{abstract}
A natureza dos problemas de pesquisa investigados já vem sendo amplamente discutida por linguistas aplicados críticos: trabalhos sobre sexo e gênero, racismo, proletarização do professor, a exclusão e ensino na escola pública, a interculturalidade na produção de textos escolares, na formação de docentes, nos currículos da escola, são temas atraentes para linguistas aplicados que querem olhar, com olhos do Sul, para o Sul, de uma posição de vantagem porque é fronteiriça e ao mesmo tempo exterior, ocupando, assim, uma terceira, diferente e privilegiada posição.
\end{abstract}

(KLEIMAN, 2013, p.50-51, negrito no original)

\title{
1. Introdução
}

Alinhando-se ao campo da Linguística Aplicada e ao grupo de pesquisa GELITUFPB, este artigo constitui um recorte de uma pesquisa mais ampla que investigou o agir linguageiro de dois licenciandos cotistas inseridos no subprojeto PIBID Letras-Inglês em uma universidade pública no nordeste (MORAIS, 2017). A presente discussão tem como objetivo geral compreender como os dizeres de licenciandos cotitas/pibidianos desvelam voz de autor, levando em conta duas entrevistas como força motriz: seguindo a proposta de autoconfrontação simples (CLOT, [1999]2007, 2010; LOUSADA, 2006), foi escolhida uma aula ministrada por cada um dos colaboradores para filmagem e posterior entrevista de autoconfrontação, que gerou o corpus de pesquisa.

Ao adotar o paradigma qualitativo, a investigação é orientada "por um conjunto de crenças e de sentimentos em relação ao mundo e ao modo como este deveria ser compreendido e estudado" (DENZIN; LINCOLN, 2006, p. 34), ancorada em gravações de aulas de língua inglesa desenvolvidas na escola-campo do PIBID. Fundamentando a investigação, é central a concepção advinda do Interacionismo Sociodiscursivo (ISD) acerca do papel fundamental da atividade linguageira no desenvolvimento humano (BRONCKART 1999; MACHADO, 2004, 2007, 2009, entre outros), sendo que neste recorte será dada ênfase aos mecanismos enunciativos, em especial, à voz do autor empírico, segundo o ISD; também é relevante o conceito de trabalho real, proposto pelas Ciências do Trabalho (CLOT,op.cit.; AMIGUES, 2004), a fim de respondermos a seguinte questão: como os dizeres de licenciandos cotistas/pibidianos desvelam voz de autor nas entrevistas de autoconfrontação? 
Em diálogo com os acima mencionados olhos do Sul - entendidos como socialmente periféricos - cabe ressaltar um aspecto relevante desta pesquisa, a saber, de que a história de dois pibidianos vem à tona devido a um projeto de mestrado engajado que leva em conta a política de ações afirmativas, pois nossos colaboradores ingressaram no ensino superior via reserva de cotas. Isto posto, situaremos brevemente, a seguir, o histórico institucional da UFPB em relação à reserva de cotas e ao PIBID.

De acordo com o dossiê intitulado Ações Afirmativas na UFPB: a longa década da democratização inconclusa no ensino superior (1999-2012) (NEABI/UFPB, 2013), as primeiras ações de mobilização para a implementação de uma política de reserva de vagas no contexto da UFPB tiveram início em 1999 por meio de professores, de pesquisadores e de estudantes inseridos nos movimentos sociais. Entretanto, apenas em 2010 a Resolução no 09/2010 é publicada aprovando a modalidade de ingresso nos cursos de graduação através das cotas. Através de uma consulta recente no Sistema de Controle Acadêmico da Coordenação do Curso de Letras do Centro de Ciências Humanas, Letras e Artes da UFPB, é possível constatar que pouco mais de um quarto (1/4) do número do total de ingressos no curso de Licenciatura em Letras-Inglês do período de 2012.1 até 2015.1 entrou por meio de algum tipo de cota.

Por sua vez, o PIBID foi criado em 2007 pelo Ministério de Educação e implementado pela CAPES/FNDE com o objetivo de valorizar o magistério e dar suporte aos estudantes de licenciatura plena das instituições federais e estaduais de educação superior. O subprojeto PIBID Letras-Inglês da UFPB iniciou-se em 2014, tendo como meta a educação inclusiva. Na época da geração do corpus, o subprojeto contava com a participação de duas professoras-coordenadoras da área de Letras-Inglês do Departamento de Letras Estrangeiras Modernas (DLEM), três professoras-supervisoras das escolas-campo e vinte e cinco licenciandos do referido curso de Letras.

Com o apoio de uma professora-coordenadora do subprojeto, verificou-se que dentre os vinte e cinco participantes do programa, sete eram cotistas. Dentre os sete, optamos por trabalharmos com a colaboração de dois deles, a saber: Madiba e Antonieta (pseudônimos) ${ }^{1}$. Sinalizando o potencial do PIBID como via de empoderamento docente,

\footnotetext{
${ }^{1}$ Vale esclarecer que a entrada dos cotistas no PIBID se deu via processo seletivo de livre concorrência.
} 
Morais (2017, p.36) afirma que "a valorização do magistério pode ser percebida também a partir dos licenciandos inseridos no programa" - ecoando Yamin, Campos e Catanante (2016, p.37), ao constatarem que "o PIBID aproximou as licenciandas de Pedagogia à profissão e revelou-lhes quão gratificante é ser uma professora".

Também vale dizer que assim como Reichmann (2015) considera o estágio supervisionado como um entrelugar (BABHA, 1998), onde os estudantes transitam entre diferentes esferas institucionais, acreditamos que o PIBID igualmente se constitui como entrelugar, onde um amplo coro de vozes dissonantes e consoantes dialoga e possibilita a emergência de novas vozes docentes.

As próximas seções se organizam da seguinte maneira: caminho teóricometodológico, discussão e, para encerrar, apresentaremos as considerações finais.

\section{Percurso teórico-metodológico}

Nesta seção, os conceitos advindos do ISD e das Ciências do Trabalho que fundamentam a discussão serão postos em cena, como também será esclarecido o procedimento de autoconfrontação, cerne da construção do corpus.

Desde o seu surgimento, a proposta teórico-metodológica conhecida por ISD tem passado por um processo de evolução, recebendo contribuições de diferentes grupos de pesquisa ao redor do mundo como, por exemplo, do grupo fundador Langage, Action et Formation (LAF) em Genebra, entre outros. Semelhantemente, pesquisadores de diversos grupos de estudo no Brasil têm contribuído para a expansão do ISD, tais como os grupos de pesquisa ATELIER (PUC/SP), ALTER (PUC/USP), LED (UEL), além do Grupo de Estudos em Letramentos, Interação e Trabalho (GELIT-UFPB), entre outros.

No Brasil, segundo Machado e Guimarães (2009), as ideias do ISD, alinhadas principalmente à Linguística Aplicada (doravante LA), marcaram as propostas de produção de documentos oficiais destinados ao ensino de textos na educação básica, por exemplo.Vale ressaltar que a LA é aqui compreendida como um modo de "[...] criar inteligibilidade sobre problemas sociais em que a linguagem tem um papel central". (MOITA LOPES, 2006, p. 14, grifo no original) e as pesquisas nessa área adotam um 
caráter crítico-reflexivo, em diálogo com demandas sociais e compromisso ético e político.

O ISD parte dos princípios fundantes do interacionismo social (VYGOTSKY, 1914; 1987), baseia-se na filosofia de Bakhtin, Habermas, Hegel, Ricoeur, Saussure, Spinoza, Marx e Engels, e tem como finalidade explicar o desenvolvimento e o funcionamento humano. Apesar de o ISD incorporar ao seu quadro conceitos originais de várias ciências - Filosofia, Sociologia, Psicologia e a Linguística - não se pode afirmar que a proposta teórico-metodológica em questão faça parte exclusivamente a alguma delas.

Segundo Bronckart (2008), o ISD propõe um procedimento metodológico descendente que se configura em três fases: (i) na análise dos pré-construídos sociais que agrupam as atividades sociais, as formações sociais conflituosas (que dão origem às regras, às normas, aos valores etc.), os textos que são frutos das atividades linguageiras e os mundos representados (mundo objetivo, mundo social e mundo subjetivo) ${ }^{2}$; (ii) na análise dos processos de formação mediada (educação informal, educação formal e transação social) que garantem a transmissão e (re)produção dos pré-construídos; e (iii) na análise dos efeitos que a formação mediada provoca na constituição e no desenvolvimento do indivíduo.

Em síntese, o ISD objetiva investigar o papel essencial da atividade de linguagem no desenvolvimento humano, tendo como unidade de análise do funcionamento humano o agir. Nesse sentido, no presente artigo focamos na corrente praxiológica dos estudos lançando mão dessa proposta teórico-metodológica ${ }^{3}$.

Como sugere Bronckart (2004), os textos podem contribuir para o processo de reconfiguração do agir, uma vez que representam o contexto social em que as ações são realizadas. O ISD compreende o texto como “[...] toda unidade de produção de linguagem situada, acabada e autossuficiente (do ponto de vista da ação ou da comunicação)" (BRONCKART, 1999, p. 75). Contudo, o agir humano não é apreensível a partir das ações humanos que podem ser observadas, mas podemos apreendê-lo por meio das

\footnotetext{
${ }^{2}$ Tal como atividades coletivas, formações sociais, textos e mundo formais de conhecimento, por ex.

${ }^{3}$ Por praxiologia entendemos o estudo das ações humanas e de como são construídas as interpretações dessas ações e dos atores sociais.
} 
interpretações dos textos. Diante disso, ressaltamos a importância de analisar os textos produzidos em situação de trabalho.

O ISD dispõe de três níveis de investigação em sua metodologia de análise dos textos/discursos, a saber: as ações semiotizadas, que estão ligadas ao mundo social e, ao mesmo tempo, são intertextuais; a arquitetura interna dos textos; e as línguas naturais e seu papel no processo de semiotização. Antes da análise propriamente dita, deve-se realizar a identificação do contexto de produção dos textos, sendo que, posteriormente, a análise textual/discursiva proposta pelo ISD se desenvolve em três níveis: (i) no nível organizacional dos textos; (ii) no nível enunciativo; e (iii) no nível semântico, (MACHADO, 2009a), como pode ser visto a seguir:

- $1^{\mathrm{o}}$ nível: Organizacional

- $2^{\circ}$ nível: Enunciativo

- $\quad 3^{\circ}$ nível: Semântico plano geral, tipos de discurso, articulações entre tipos de discurso, sequências textuais, mecanismos de textualização

vozes, modalizações, índices de pessoa

figuras de ação, tipos de agir

Levando em consideração o objetivo geral deste trabalho em questão compreender como os dizeres de licenciandos cotistas/pibidianos desvelam voz de autor - será focalizado o nível enunciativo. Conforme Machado e Bronckart (2009), os mecanismos enunciativos podem ser identificados a partir de unidades linguísticas tais como índices de pessoa, vozes e modalizações, responsáveis pela coerência pragmática do texto. Ecoando a noção bakhtiniana de voz, segundo Bronckart (1999, p. 326), "as vozes podem ser definidas como as entidades que assumem (ou às quais são atribuídas) a responsabilidade do que é enunciado". O autor organiza as vozes em vozes de personagens, vozes sociais e voz do autor (empírico), esta constituída pela voz do enunciador intervindo, avaliando e comentando os aspectos enunciados.

Como já sinalizado, enfatizaremos a categoria voz do autor empírico constituída por estudantes inseridos no Pibid e, para tanto, é importante a análise dos dados selecionados para esse artigo, visto que acreditamos que ao identificarmos tal voz nos comentários dos participantes, podemos vislumbrar constituição identitária profissional: 
ecoando Böhn, (2004, p.97), retomamos a noção de que "a identidade social do professor se constitui por meio de um coro de vozes de outros (interiorizadas) e de si (internas), que ecoa em textos empíricos escritos por professores iniciantes” (REICHMANN, 2015, p.64).

Em termos do ensino como trabalho, segundo Machado (2007, p.84), o trabalho docente "engaja a totalidade do humano e potencializa o desenvolvimento de suas capacidades". A partir dessa concepção, vários pesquisadores têm lançado um olhar sobre o trabalho do professor, com o objetivo de investigar a docência enquanto atividade profissional. Nesses termos, situado na Ergonomia do Trabalho, Amigues (2004, p.46) considera que o trabalho de ensino consiste em conceber, organizar e regular o meio de trabalho dos alunos. O autor (2004, p.48, grifo no original) também aponta que

[p]ara o professor, gerir a classe é construir as dimensões coletivas da ação individual, e ter uma classe que funciona é não só ter bons alunos, mas um coletivo coeso soldado e pronto para se engajar na ação: coesão do grupo e coerência das aquisições sustentam-se mutuamente.

De acordo com Bronckart (2008), o trabalho é uma maneira de agir, pois o trabalhador exerce um papel interventivo - coletiva e individualmente - no mundo através de razões e habilidades. As intervenções coletivas são conhecidas como atividade e as individuais, como ação. O agir é constituído de atividades e ações, sendo estas influenciadas física e socialmente. Nesse sentido, o agir reúne os trabalhadores a partir de características comuns como, por exemplo, professores, médicos, fisioterapeutas, e assim por diante.

No âmbito das pesquisas realizadas pelo referido GELIT-UFPB, o diálogo acadêmico entre o ISD, a Clínica da Atividade e a Ergonomia da Atividade tem sido profícuo, focalizando, por exemplo, o trabalho prescrito e trabalho real. As prescrições são inerentes a toda atividade profissional e, nessa perspectiva, Amigues (2004, p.42) assevera que "[...] o trabalho do professor inscreve-se em uma organização com prescrições vagas, que levam os professores a redefinir para si mesmos as tarefas que lhes são prescritas, de modo a definir as tarefas que eles vão, por sua vez, prescrever aos alunos". Segundo o autor, as tarefas são compreendidas como o que deve ser feito e as atividades como o esforço mental de um indivíduo em realizar uma determinada tarefa. 
No tocante ao trabalho real, conceito relevante nesta pesquisa, Amigues (2004, p. 40) reitera que o desenvolvimento profissional e pessoal do trabalhador se dá por meio do embate entre o trabalho prescrito e o trabalho real. Clot ([1999]2007), afirma que a atividade transcende aquilo que é realizado pelo indivíduo, contemplando, igualmente, aquilo que se conseguiu realizar ou não, devido a obstáculos imprevistos. Nessa linha, ecoando Vygotsky (1925/1994, apud CLOT, [1999]2007, p.115), é relevante ressaltar que “[o] homem está a cada minuto pleno de possibilidades não realizadas", e como implicação, entende-se que "o real da atividade é também aquilo que não se faz, aquilo que não se pode fazer, aquilo que se busca fazer sem conseguir - os fracassos [...]" (CLOT, op. cit., p. 116). Em outras palavras, elabora-se sobre a dialética que sempre vai existir entre o trabalho que foi planejado e o que foi, na verdade, realizado. Portanto, a atividade não realizada, aquela que foi impedida ou deixada de lado, não pode ficar de fora de uma análise do trabalho, haja vista que ela lança "todo o seu peso sobre a atividade presente" (CLOT, 2007, p. 116).

A título de esclarecimento, Medrado (2017, p.165) nos remete à imagem do iceberg como metáfora do trabalho docente, como pode ser visto a seguir:

\begin{abstract}
A ponta do iceberg constituindo-se o que podemos perceber em sala de aula como observadores externos. Invisível é, exatamente, o que está submerso, e apenas o professor pode explicar o que está além do que não conseguimos capturar: como contornou as tensões que apareceram em sala; como reorientou seu plano e atividades; e a partir de quais critérios; quais momentos motivaram-no a fazer determinada intervenção ou modificar estratégias etc.
\end{abstract}

Na busca pela interpretação do trabalho real (submerso, invisível), empreendido pelos pibidianos em cena, lembramos que foi escolhida uma aula ministrada por cada um dos colaboradores para filmagem; as discussões sobre as próprias filmagens também foram filmadas (isto é, as entrevistas de autoconfrontação) e compõem o conjunto de dados analisados no presente artigo.

Em outras palavras, nossas entrevistas de autoconfrontação constituem uma interação situada, onde se criou um coletivo de trabalho, qual seja, um grupo de professores iniciantes no PIBID. O pesquisador observou as situações de trabalho, enquanto os membros do coletivo de trabalho esquematizaram as atividades a serem 
realizadas, as atividades foram gravadas pelo pesquisador e, por fim, o trabalhador se confrontou com suas próprias imagens ao realizar seu trabalho e teceu comentários acerca de tal vivência, gerando a entrevista gravada.

Segundo Clot (2010, p. 241, grifo do autor), “[e]sse movimento de confrontação dialógica sobre a atividade de trabalho é, a priori, ilimitado. A última palavra não pode ser dita". Ao passo que os participantes observam o seu agir na atividade profissional e refletem sobre este agir, simultaneamente podem se desenvolver e se transformar. Nesses termos, Clot (2007, p. 137) afirma que "não basta só compreender para transformar, mas também transformar para compreender".

Em suma, as filmagens foram realizadas em dias e horários previamente agendados com os colaboradores, as entrevistas de autoconfrontação também foram gravadas e, posteriormente, transcritas para análise. Da análise do texto transcrito, emergiram os principais temas, a saber, conflitos no contexto da docência, surpresas e apropriação do gênero profissional docente. Neste artigo, com foco em fragmentos relativos ao tema conflitos, buscamos analisar seis excertos, três do colaborador Madiba e três da colaboradora Antonieta.

Na próxima seção, apresentaremos a análise dos dados.

\section{Discussão: Três lanches, professora?}

Ao analisarmos os textos gerados a partir da entrevista de autoconfrontação com os colaboradores pibidianos, verificaremos a voz de autor empírico que emerge no âmbito do tema conflitos no contexto da docência. Tratando de questões como uso da língua materna e da língua-alvo, escrita e oralidade, trabalho social, bullying e carência alimentar, apresentaremos seis fragmentos emblemáticos extraídos dos textos produzidos pelos colaboradores ao se verem nas filmagens. Como será visto ao longo da discussão, é de especial interesse a voz autoral do professor engendrada a partir dos conflitos emergentes, ou seja, sinalizada pelo trabalho real.

Verificou-se que a interpretação que os pibidianos oferecem do seu próprio agir revela tanto conflitos internos, em relação aos conteúdos e à metodologia das aulas, por exemplo, como também revela conflitos externos, relativos à vida dos alunos que, muitas vezes, está relacionada a contextos socioeconomicamente desfavorecidos. 
No âmbito dos conflitos internos, iniciaremos com a seguinte fala, sobre a escolha da língua, como pode ser visto abaixo:

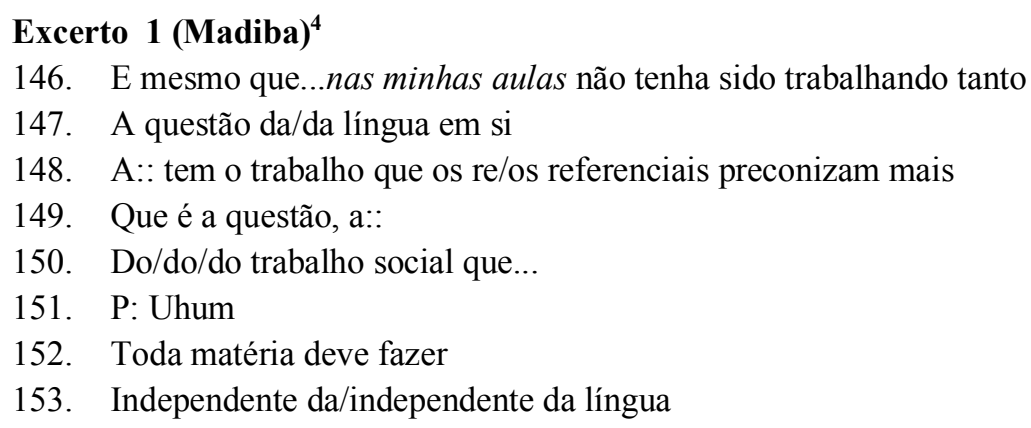

Neste fragmento, o professor iniciante traz para sua fala a voz social dos documentos oficiais para o ensino que preconizam o ensino por meio de temas transversais. Segundo os Parâmetros Curriculares Nacionais (BRASIL, 1998), tais temas apontam para conceitos e valores elementares a cidadania tais como ética, meio ambiente, saúde, trabalho e consumo, orientação sexual e pluralidade cultural. É interessante refletir em que medida outros aspectos que não a língua são focados; percebe-se que Madiba salienta seu trabalho com os temas transversais, a fim de favorecer um trabalho social (como será visto adiante no fragmento 5), revelando uma postura que se alinha aos referenciais.

Por sua vez, Antonieta busca a língua inglesa em sua aula e, além disso, defende que a língua e, principalmente, a oralidade, ocupem um espaço relevante na sua sala. No fragmento abaixo, pode-se ver seu posicionamento:

\section{Excerto 2 (Antonieta)}

291. Uma das coisas que eu acho... errado

292. pelo menos na sala de aula de língua inglesa

293. é:/é não ter essa prioridade na fala.

294. Eu acho isso uma crucificação porque, por exemplo...

295. pra um aluno desenvolver as quatro habilidades na língua

296. ele precisa da fala

297. e: como os referenciais, né.

298. E:: também a LDB ela não dá prioridade a fala

299. e eu não sei se/se isso vem também do domínio do professor também

300. MAS... como essa escola assim

\footnotetext{
${ }^{4}$ Sobre as linhas, foi mantida a numeração da transcrição na dissertação. P refere-se ao pesquisador.
} 


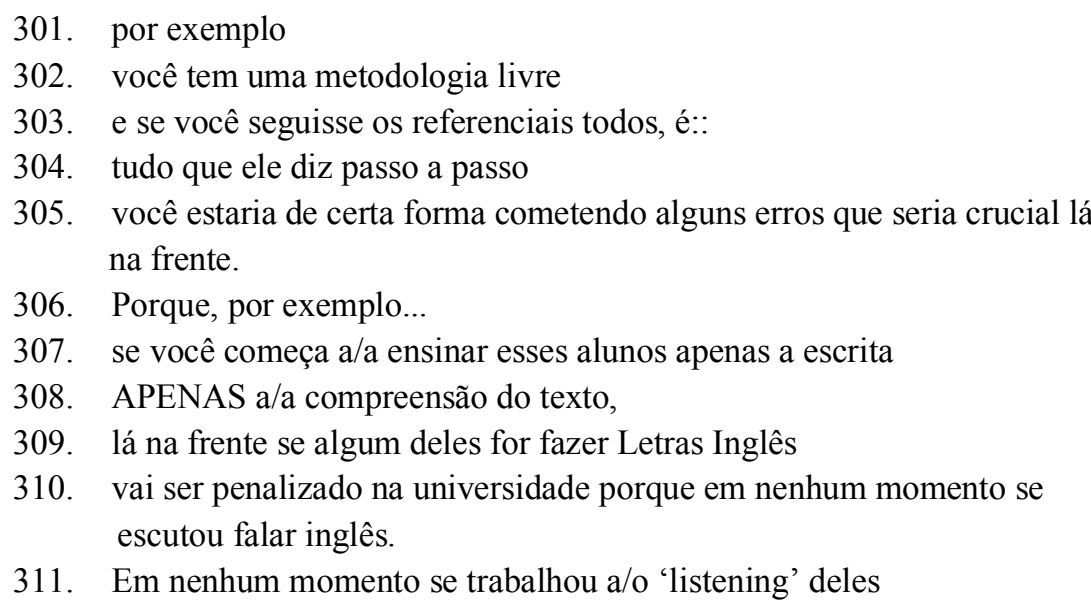

Nos trechos destacados em itálico, podemos perceber a voz de autor empírico. Assim como Madiba, Antonieta também traz a voz social dos documentos oficiais, contudo, a colaboradora sugere um tom de reprovação quanto ao fato dos documentos desconsiderarem a produção oral. A reprovação é tão evidente que Antonieta usa a metáfora da crucificação: isto é, negligenciar a fala em aulas de língua inglesa, para a colaboradora, é sinônimo de sofrimento, de morte. Ou seja, seus dizeres sugerem que o aluno da rede pública de ensino é penalizado por não ter acesso à oralidade desde o início de sua formação. Nesse sentido, no texto se constrói a voz de autor empírico, dissonante, se opondo às prescrições estabelecidas pelos documentos oficiais. Nota-se também um 'você', entendido como professor genérico, em oposição aos referenciais - pois nesta questão, Antonieta acredita que seguir os documentos oficiais ao pé da letra, com foco na escrita, seria cometer alguns erros que seria crucial lá na frente: a pibidiana chega a posicionar seus alunos como possíveis estudantes de Letras-Inglês, reiterando um tempoespaço lá na frente, e aludindo à sua própria história de vida, como será visto no fragmento adiante.

$\mathrm{Na}$ linha 299, a colaboradora menciona a possibilidade do professor não ter domínio da língua e, consequentemente, não priorizar a língua em suas aulas, devido a uma lacuna na própria aprendizagem. A colaboradora, ao atentar para esse fato, pondera sobre a importância de se trabalhar o ensino de inglês nas séries iniciais do ensino regular, pautado no desenvolvimento das outras habilidades além da compreensão escrita.

Ou seja, em relação aos documentos oficiais, ao trazê-los para sua fala, Madiba adere aos postulados de que se deve trabalhar os temas transversais de maneira 
construtivista, não só pautada na língua alvo e, nesse sentido, justifica suas ações em sala de aula e sua visão de docência. Dito isso, outra voz autoral se opõe às prescrições dos documentos oficiais que não valorizam a oralidade em sala de aula de língua inglesa no Ensino Fundamental. Embora, os pibidianos assumam posturas diferentes em relação às prescrições sugeridas pelos PCNs, podemos perceber o desenvolvimento profissional e pessoal de Madiba e Antonieta, uma vez que, como afirma Amigues (2004), é por meio do embate entre o trabalho prescrito e o realizado que ocorre tal desenvolvimento. A postura de aceitação e/ou negação das prescrições demonstra o caminho escolhido pelos licenciandos visando à efetividade de 'ter uma classe que funciona'.

Como pode ser visto a seguir, Antonieta compartilha sua difícil experiência pessoal enquanto aluna de licenciatura em Letras,

\section{Excerto 3 (Antonieta)}

322. e pretendo quando começar a ensinar profissionalmente não cometer esses erros

323. que eu acho que:: uma das coisas quando eu cheguei aqui na universidade

324. e:: que não tive a: oportunidade de estar na sala de aula escutando o inglês e falando o inglês

325. isso me acarretou... por exemplo, uma reprovação porque eu tinha medo de falar

326. eu tinha medo de falar errado e::

327. se começar a construir com os meus alunos esse passo a passo

328. deles falarem, deles escutarem e/e/e trabalhar essa habilidade,

329. quando ele chegar lá na frente se... caso não forem fazer curso de Letras Inglês

330. ou por exemplo, se forem fazer outras coisas na vida

331. se encontrar um estrangeiro na rua vai poder falar

332. se comunicar o mínimo possível

333. mas também vai haver essa comunicação.

334. Então... assim...

335. se o ensino é pra vida,

336. se você ensina a criança e esse ensino é pra que tenha alguma utilidade na vida,

337. então eu acho importantíssimo a fala.

Antonieta assume um compromisso de não cometer o que ela entende por erro, quando estiver ensinando profissionalmente. Justifica seu posicionamento trazendo uma voz do passado, sua voz de estudante ao ingressar na universidade, com as dificuldades que sentiu com o uso da língua, visto que, por ser egressa do ensino público e por não ter 


\section{The ESPecialist: Descrição, Ensino e Aprendizagem, Vol.39 No. 1 jan-jul 2018 https://revistas.pucsp.br/esp CThe ESPecialist}

ISSN 2318-7115

tido a oportunidade de escutar e de falar o inglês na sala de aula, ocasionou medo e reprovação. Mais uma vez, percebe-se que os pré-construídos da colaboradora parecem ser fundamentais para enxergar uma necessidade no ensino público e, além disso, para querer fazer diferente. Antonieta não deseja que seus alunos passem pelo que ela passou. E, nesse sentido, visa desenvolver um ensino que seja útil para seus alunos, visto que, segundo Antonieta, o ensino é pra vida. Percebe-se claramente uma voz de autor empírico, revendo sua vivência como estudante universitária no início do curso e, agora, como pibidiana.

No excerto 4 a seguir, o colaborador aborda um conflito interno da sala de aula que afeta o professor, a saber, a indisciplina dos alunos que surge na forma do barulho da sala de aula. Muitos profissionais da docência se queixam dessa problemática e atribuem a falta de estímulo para o ofício do professor como consequência.

\section{Excerto 4 (Madiba)}

220. Madiba: Acho que... você se,

221. eu não me visualizo tanto no oficio de professor.

222. Ah, mesmo que eu estude uma licenciatura

223. e acho que isso é muito comum entre alunos, assim...

224. porque quando a gente entra numa sala de aula

225. que a gente vê tanto barulho, tanta coisa...

226. parece que pouca coisa funcionou naquela aula, assim...

227. Mas a gente analisando de fora,

228. a gente percebe que não tão pouca coisa funcionou assim.

229. Ah, que essa barulheira... esse, acho que faz parte do contexto da adolescência mesmo.[...]

254. Acho que dá pra se vis/ visualizar um pouquinho mais no ofício.[...]

442. Madiba: Acho que, a:::

443. tem uns momentos assim que,

444. embora eu não pareça estressado

445. dá essa sensação de que foi momentos de estresse. (Madiba bate com a caneta na carteira mostrando como ele agia durante a aula para chamar atenção dos alunos)

446. P: Aham

447. Madiba: É: pra chamar atenção mesmo dos alunos, assim

448. talvez seja necessário em algum momento, mas

449. acho que se dá pra ir evitando e tal.

Madiba inicialmente revela que não se percebia professor, ou seja, a sua identidade profissional ainda não está visível. As razões dadas pelo colaborador para 
justificar seu sentimento de não pertencimento ao coletivo de professores foram o barulho da sala de aula, as dificuldades para executar as atividades como planejadas e o descaso dos alunos com as aulas. A voz do autor empírico, nesse excerto, sinalizado por acho que, desvela um processo de tornar-se professor, isto é, na tensão entre o ser e o não ser professor, diante dos fatores inerentes ao exercício da docência que marcam positiva e negativamente o trabalhador. Madiba, em constante (des)construção identitária, passa a se visualizar um pouquinho mais no oficio.

Assim como Madiba, outros professores se sentem afetados por conflitos internos da sala de aula como, por exemplo, o barulho, indisciplina e descaso dos alunos. Todavia, o pibidiano consegue perceber, em outro momento, que muito do que ele havia planejado foi executado. Tal percepção é importante, pois Madiba consegue se enxergar professor e avaliar que, o que antes era conflito - barulho, indisciplina - é algo inerente aos estudantes daquela idade.

Mais uma vez, a autoconfrontação desvela aspectos do trabalho real e o colaborador reconhece que, apesar do impedimento vivenciado pelo barulho, o trabalho foi bem sucedido. Diante disso, podemos relembrar que o trabalho real transcende o que é realizado pelo trabalhador (Clot, 2007). Isto é, Madiba percebe que as adaptações, contornos e mudanças de plano conseguiram superar o obstáculo da indisciplina, do barulho e, assim, ajudou-o a reconhecer-se como professor. Madiba redimensiona, nos termos de Amigues (2004), sua compreensão de 'ter uma classe que funciona'.

Em relação aos conflitos externos, nos fragmentos 5 e 6 a seguir percebe-se a sensibilidade que os colaboradores, enquanto docentes em formação, demonstram em relação às condições sociais e subjetivas de seus alunos como, por exemplo, a recorrência de bullying na escola e carência de alimentação.

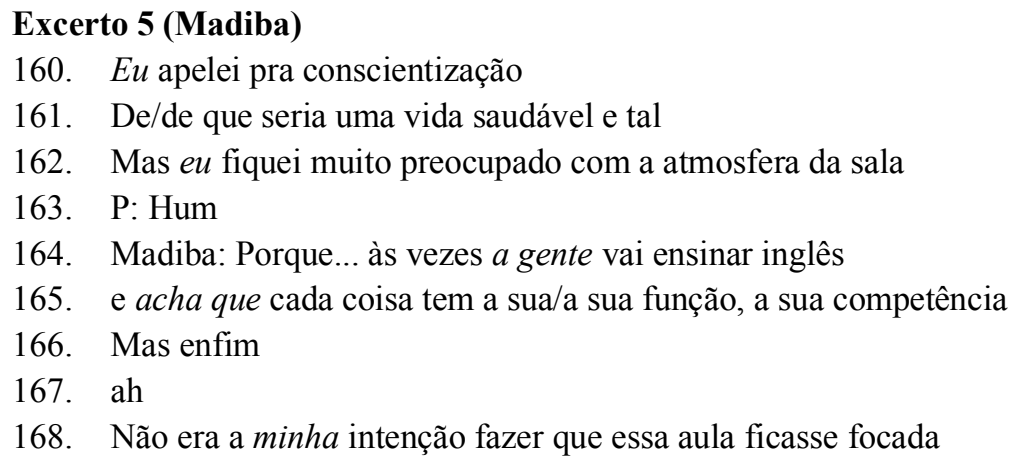


exatamente na língua inglesa.

169. Porque essa é uma escola que tem sofrido

170. É::

171. Muitos casos de/de a:: bullying

172. Muitos casos de a: preconceitos, digamos assim.

173. E:: quando $a$ gente vai tratar de qualquer tema

174. parece ser meio tenso.

175. Parece que há um clima meio/meio pesado e tal.

176. E eu quis deixar uma atmosfera mais agradável pra os alunos

177. aprenderem um pouco da língua,

\section{Excerto 6 (Antonieta)}

180. Antonieta: Uma das coisas que eu percebi que:

181. quando $e u$ comecei a dar/dar essa aula

182. quando $e u$ comecei a falar sobre as refeições

183. que $a$ gente precisava de fazer seis refeições diárias.

184. E aí que $a$ gente tinha três lanches,

185. eu percebi que: eles não têm todas as refeições

$[\ldots]$

189. Antonieta: você percebe pelas respostas que eles dão

190. "OXENTE, são três lanches... três lanches, professora?"

191. "Como é que são esses lanches?"

192. Aí eu passei a explicar a eles:

193. "um depois do café da manhã, um depois do almoço, um depois do jantar".

194. E a gente percebe a carência na questão da alimentação

O contexto socioeconômico dos alunos está relacionado diretamente com suas vidas escolares/acadêmicas e, em alguns casos, como sinalizam Moura e Souza Junior (2015), o contexto precário é a causa da evasão de alunos nos cursos de licenciaturas; na educação básica, talvez, isto seja bem mais visível. Ou seja, as condições sociais e subjetivas dos alunos são fatores preponderantes no processo educacional e os exemplos na fala dos colaboradores, destacados, apontam para esse fator. Se por um lado, o grupo de alunos de Madiba o leva a lidar com impedimentos como preconceito e bullying, que direciona o trabalho do professor iniciante pela língua materna, a fim de poder lidar com tal problema social, semelhantemente, o grupo de Antonieta retrata um problema social básico - a fome - exemplificado pelos dizeres dos alunos e marcado pelo enunciado eu percebi que eles não têm todas as refeições ${ }^{5}$. Vale também mencionar que enquanto a

\footnotetext{
${ }^{5}$ É mais do que sabida a importância vital da merenda escolar.
} 
gente, nos dizeres de Madiba apontam para o coletivo de trabalho do PIBID, na fala de Antonieta, a gente ora se refere à turma, ora se refere ao grupo do PIBID, enfatizando a importância do Outro com elemento constitutivo do trabalho docente (AMIGUES, 2004) e que, como coletivo de trabalho, orientou-se pela educação inclusiva.

Não se pode afirmar com precisão se tal sensibilidade demonstrada pelos colaboradores é decorrente de uma identificação com as condições sociais e/ou subjetivas dos alunos, visto que ambos os colaboradores foram egressos do ensino público e, em alguma medida, socioeconomicamente afetados. Contudo, pode-se concluir que os préconstruídos, nos termos bronckartianos, são fundamentais na geração de valores e, por conseguinte, nas avaliações sociais. Pode-se inferir que, de alguma forma, os licenciandos cotistas/pibidianos conseguem interpretar o que outros talvez não conseguissem. As falas destacadas pelos colaboradores lembram um contexto social afetado por dificuldades e limitações de ordem econômica: percebe-se que escolhas enunciativas marcadas por eu acho, eu percebi constituem vozes de autor empírico e são reveladoras quanto à construção identitária.

Em suma, considerando o tema conflitos no contexto da docência, nota-se que a voz do autor empírico se constitui por meio de conflitos internos e externos, visibilizados pelo agir linguageiro, a saber, dizeres decorrentes de textos produzidos em situação de trabalho.

\section{Considerações finais: olhos do Sul, para o Sul}

A título de fechamento, voltamos à pergunta inicial, ou seja, como os dizeres de licenciandos cotistas/pibidianos desvelam voz de autor nas entrevistas de autoconfrontação? Por meio dos conflitos assinalados - barulho e bullying, oralidade e fome - destacamos a voz de autor empírico, enunciada por estudantes pibidianos que, atentos em ter uma classe que funcione (AMIGUES, 2004), assumem posturas diferentes em seu agir, demonstrando, assim, constituições identitárias profissionais situadas e plurais, seja pela escolha de qual língua usar em sala de aula, seja pela visão que constroem sobre oralidade e escrita (em diálogo com os referenciais, com o Outro e com si mesmo), assim pondo em evidência um aspecto apontado na epígrafe - a exclusão e a escola pública. Podemos concluir que a análise do trabalho real emergente nas 
autoconfrontações revela embates que permitem a inscrição da voz de autor empírico, apontando para o potencial do Pibid como entrelugar de desenvolvimento socioprofissional, onde, em meio a um coro de vozes, pode emergir a voz de professorautor.

E por fim, dialogando com a epígrafe, Kleiman (2013, p.58) salienta a relevância da utopia, ao frisar que "se a utopia está no horizonte, afastando-se à medida que nos aproximamos, indicando um caminho, não vejo por que os caminhos da LA, seja atrás da pesquisa ou da ação social, não deveriam ser 'suleados' por essa utopia". Nesta linha de raciocínio, entendemos que as pesquisas em LA no Brasil possuem um caráter próprio, de suleamento, e que o presente trabalho se insere nesse paradigma, ancorado em questões de responsabilidade social. Ao analisarmos os dizeres de licenciandos cotistas no subprojeto de Letras-Inglês do PIBID, desvela-se a voz de autor empírico, vêm à tona histórias de formação inicial que iluminam a vida na academia e na escola, possibilitando, apesar de tantos obstáculos, novos horizontes e novas vozes docentes.

\section{Referências Bibliográficas}

AMIGUES, R. 2004. Trabalho do professor e trabalho de ensino. In: A.R. MACHADO, O Ensino como trabalho: uma abordagem discursiva. Londrina: Eduel, pp. 37-53.

BABHA, H. K. 1998. O lugar da cultura. Belo Horizonte: Editora da UFMG.

BÖHN, H. I. 2004. A formação do professor de línguas: a construção de uma identidade profissional. Investigações - linguística e teoria literária. Recife: UFPE, 17: 97-113.

BRASIL.1998. Secretaria de Educação Fundamental. Parâmetros Curriculares Nacionais: terceiro e quarto ciclos do ensino fundamental: língua estrangeira. Brasília: $\mathrm{MEC} / \mathrm{SEF}$.

BRONCKART, J. P. 1999. Atividade de linguagem, textos e discursos: por um interacionismo sociodiscursivo. São Paulo: Educ.

. 2006. Atividade de linguagem, discurso e desenvolvimento humano. Campinas: Mercado de Letras.

. 2008. O agir nos discursos: das concepções teóricas às concepções dos trabalhadores. Campinas: Mercado de Letras.

CLOT, Y. [1999]2007. A função psicológica do trabalho. $2^{\mathrm{a} e d . ~ T r a d .: ~ A d a i l ~ S o b r a l . ~}$ Petrópolis: Vozes. 2010. Trabalho e o poder de agir. Belo Horizonte: Fabrefactum. 
DENZIN, N. K.; LINCOLN, Y. S. 2006. Introdução: a disciplina e a prática da pesquisa qualitativa. In: N. K, DENZIN; Y. S. LINCOLN. O planejamento da pesquisa qualitativa: teorias e abordagens. Porto Alegre: Artmed, pp. 15-42.

DOSSIÊ Ações Afirmativas na UFPB. 2013. A longa década da democratização inconclusa no ensino superior (1999-2012). João Pessoa: NEABI/CCHLA.

KLEIMAN, Angela B. 2013. Agenda de pesquisa e ação em Linguística Aplicada: problematizações. In: L. P. MOITA-LOPES (Org.). Linguística Aplicada na modernidade recente: festschrift para Antonieta Celani. São Paulo: Parábola, pp. 39-58.

LOUSADA, E. G. 2006. Entre trabalho prescrito e realizado: um espaço para a emergência do trabalho real do professor. Tese de Doutorado. São Paulo: Pontifica Universidade Católica de São Paulo.

MACHADO, A. R. 2004. O ensino como trabalho: uma abordagem discursiva. Londrina: EDUEL; São Paulo: FAPESP.

. 2007. Por uma concepção ampliada do trabalho do professor. In: A. M. M. GUIMARÃES; A. R. MACHADO; A. COUTINHO (Orgs.) $O$ interacionismo sociodiscursivo: questões epistemológicas e metodológicas. Campinas: Mercado de Letras, pp. 77-97.

MACHADO, A. R. et. al. 2009. Linguagem e educação: o trabalho do professor em uma nova perspectiva. Campinas: Mercado de Letras.

MACHADO, A. R.; BRONCKART, J. P. 2009. (Re-)configuração do trabalho do professor construídas nos e pelos textos: a perspectiva metodológica do grupo ALTERLAEL. In.: A. R. MACHADO et al. 2009a. Linguagem e educação: o trabalho do professor em uma nova perspectiva. Campinas: Mercado de Letras.

MEDRADO, B. P. 2017. Tornando-se professor: a compreensão de graduandos em Letras sobre a atividade educacional. In: B.P MEDRADO, B. P.; C.L.REICHMANN, Projetos e práticas de professores de língua inglesa (ebook, 2a ed.). João Pessoa: Editora Universitária da UFPB, 2017. Acesso em: 14 de março de 2018.Disponível em: http://www.editora.ufpb.br/sistema/press/index.php/press/catalog/book/212.

MOITA-LOPES, L. P. 2006. Por uma Linguística Aplicada Indisciplinar. SP: Parábola.

MORAIS, D.S. Uma análise do agir linguageiro de licenciandos cotistas no PIBID/Letras-Inglês. Dissertação de Mestrado. João Pessoa: UFPB, 2017.

MOURA, E. M.; SOUZA JUNIOR, A. J. 2015. Saberes docentes sobre o trabalho educativo no projeto PIBID. In.: M. V. BARBOSA; A. R. GONÇALVES; B. GAYDECSKA et al. A boniteza de ensinar e a identidade do professor na contemporaneidade. Campinas, São Paulo: Mercado das Letras, pp. 289-310.

REICHMANN, C.L. 2015. Letras e letramentos: escrita situada, identidade e trabalho docente no estágio supervisionado. Campinas: Mercado de Letras.

VYGOTSKY, L. S. 1984. A formação social da mente. São Paulo: Martins Fontes. . 1987. Pensamento e Linguagem. São Paulo: Martins Fontes. 
YAMIN, G. A.; CAMPOS, M. I.; CATANANTE, B. R. 2016. "Quero ser professora": a construção de sentidos da docência por meio do Pibid. Revista Brasileira de Estudos Pedagógicos. 97.245:31-45. Disponível online em: http://dx.doi.org/10.1590/S21766681/3368314027. Acesso em: 20 de janeiro de 2017.

Carla Lynn Reichmann holds a Ph.D. in Letters (UFSC, 2001), and developed her postdoctoral project in Applied Linguistics (UNICAMP, 2012). Associate professor at UFPB, in the Foreign Letters undergraduate department and Linguistics graduate school, her research interests include language teacher literacy and identity practices. Email: carlareichmann@hotmail.com

Daniel Sousa Morais holds a degree in English Language and Literature (UFPB, 2013), and an MA in Linguistics (UFPB, 2017). Member of the research group Literacies, Interaction and Labor (GELIT-UFPB/CNPq), his research interests address Applied Linguistics and Teacher education, in line with Sociodiscursive Interactionism. Email: daniel_smorais@hotmail.com 